\title{
The Effect of Curcumin on Patients with Chronic Fatigue Syndrome/Myalgic Encephalomyelitis: An Open Label Study
}

\author{
C. (Linda) M. C. van Campen"1, K. Riepma ${ }^{2}$, Frans C. Visser ${ }^{1 *}$ \\ ${ }^{1}$ Stichting Cardiozorg, Hoofddorp, Netherlands \\ ${ }^{2}$ Curesupport, Valkenburg, Netherlands \\ Email: *info@stichtingcardiozorg.nl
}

How to cite this paper: van Campen, C. (L) M.C., Riepma, K. and Visser, F.C. (2018) The Effect of Curcumin on Patients with Chronic Fatigue Syndrome/Myalgic Encephalomyelitis: An Open Label Study. International Journal of Clinical Medicine, 9, 356-366.

https://doi.org/10.4236/ijcm.2018.95031

Received: March 10, 2018

Accepted: May 6, 2018

Published: May 9, 2018

Copyright $\odot 2018$ by authors and Scientific Research Publishing Inc. This work is licensed under the Creative Commons Attribution International License (CC BY 4.0)

http://creativecommons.org/licenses/by/4.0/

\section{c) (i) Open Access}

\begin{abstract}
Myalgic encephalomyelitis/chronic fatigue syndrome (ME/CFS), recently renamed as systemic exertion intolerance disease (SEID), is a chronic and often disabling disease. Although the exact pathophysiological mechanism of ME/CFS is unknown, immunological abnormalities may play an important role. Curcumin is a herb with powerful anti-oxidative, and anti-inflammatory properties. Therefore, we hypothesized that curcumin has favorable effects on symptomatology in ME/CFS patients. In total 52 patients participated, nine stopped the use of curcumin because of side effects. All remaining patients ( $\mathrm{n}$ = 43) met the criteria for CFS; $72 \%$ met the criteria for ME. Before and 8 weeks after the use of curcumin complexed with phosphatidyl choline, $500 \mathrm{mg}$ bid, the CDC inventory for assessment of Chronic Fatigue Syndrome was filled in. The CDC questions $(n=19)$ were scored and divided into 2 parts: the first being specific for CFS complaints $(n=9)$, the second being scores of less specific symptoms $(n=10)$; denoted as CDC rest score. Results showed that 8 weeks curcumin use significantly decreased the CFS related symptom scores, but not the CDC rest scores. Analyzing the data separately for ME and CFS patients, the same significance for the CFS symptom scores was present. Conclusion: in this open-labeled study, 8 weeks curcumin use in a phosphatidyl choline complex reduced ME/CFS symptomatology. Therefore, a randomized placebo controlled study is warranted to assess its efficacy in $\mathrm{ME} / \mathrm{CFS}$ patients.
\end{abstract}

\section{Keywords}

Curcumin, Chronic Fatigue Syndrome, Myalgic Encephalomyelitis, CDC CFS Symptom Inventory 


\section{Introduction}

Curcumin is a herb with powerful anti-oxidative [1], anti-inflammatory [2], anti-mutagenic [5] and anti-microbial properties [3] [4]. Multiple studies have demonstrated that curcumin exerts its anti-oxidative effects by inhibition of superoxide radicals, hydrogen peroxide and nitric oxide radicals [1]. Other studies demonstrated that curcumin also increases the activity of many anti-oxidant enzymes such as catalase [6], superoxide dismutase (SOD) [7], glutathione peroxidase [8] and hemeoxygenase-1 [9].

Oxidative stress can lead to chronic inflammation [10]. ROS production modulates the expression of NF-kappa B and TNF- $\alpha$ pathways which play a central role in the inflammatory response [11]. Curcumin can decrease TNF- $\alpha$ production and block NF-kappa B [12]. Curcumin also inhibits inflammatory cytokines, such as interleukins [13] [14], chemokines [15], as well as inflammatory enzymes, such as cycloxygenase-2 (COX-2) [16], inducible nitric oxide synthase (iNOS) [17] and others molecules like cyclinD1 [18] (see for extensive reviews in Ref. [19] and [20]).

Therefore, curcumin has been studied in inflammatory diseases like asthma [21], rheumatoid arthritis [22], inflammatory bowel disease [23], Alzheimer [24], mood disorders [25], cancer [26], diabetes [27], pain [28] and cardiovascular disease [29]. Although the animal experimental studies are overwhelmingly positive, the data of patient studies are limited. Thus the role of curcumin as a clinical therapy has yet to be established.

Myalgic encephalomyelitis/chronic fatigue syndrome (ME/CFS), recently renamed as systemic exertion intolerance disease (SEID) in the US [30], is a chronic and often disabling disease. The exact prevalence is unknown but estimates in the US vary between 850,000 and 4 million patients, in the Netherlands between 20,000 and 80,000 patients. Patients with ME/CFS have been found to be more functionally impaired than those with other disabling illnesses [30] [31] [32]. Although the exact pathophysiological mechanism of ME/CFS is unknown, immunological abnormalities may play an important role. Oxidative stress is increased [33] [34] [35] [36] [37] in ME/CFS patients. The data on cytokines are conflicting and a recent meta-analysis [38] showed no overall change for the 77 plasma cytokines studied in ME/CFS patients compared to controls, with the possible exception of TGF- $\beta$ increase in ME/CFS. On the other hand, recent studies showed that cytokines may be used as a biomarker when taking the illness duration into account [39] [40] [41]. Also, cytokines in cerebrospinal fluid show a distinct pattern in ME/CFS patients [42]. Because of the anti-oxidative and anti-inflammatory properties of curcumin, we hypothesized that curcumin has favorable effects on symptomatology in ME/CFS patients. This hypothesis was supported by a study in a chronic fatigue mouse model during water immersion stress testing. In this study, curcumin decreased immobility time, and oxidative stress and TNF- $\alpha$ levels [43]. 


\section{Patients and Methods}

Patients with ME/CFS were asked to participate in the registry and gave informed consent. All fulfilled the Fukuda criteria for CFS [44]. Also, patient complaints were scored according to the ME criteria [45]. Patients were classified as ME or atypical ME. Patients were asked to fill-in the CDC inventory for assessment of Chronic Fatigue Syndrome [46], Dutch language version [47], prior to the start of using curcumin and return the questionnaire by post or email. After 8 weeks of curcumin use, the same questionnaire was filled in. Patients used Curcumin Phytosome (Curcuma longa extract complexed with phosphatidyl choline; $\left.\mathrm{NOW}^{\circledR}\right) 500 \mathrm{mg}$ capsules twice a day. According to the manufacturer the capsules contained minimally $18 \%$ ( $90 \mathrm{mg}$ ) curcuminoids.

In total 58 patients participated. 6 patients stopped the use of curcumin because of side effects, of 8 patients the second questionnaire was not returned, despite two reminders. They were also excluded, leaving 44 patients for the final analysis. The work described has been carried out in accordance with The Code of Ethics of the World Medical Association (Declaration of Helsinki) for experiments involving humans. The medical ethics committee of the Slootervaart Hospital, Amsterdam, NL, approved the study (code U/17.089/P1736).

\subsection{Data Analysis}

The CFS CDC inventory contains 19 symptom questions and collects information about the presence, frequency, and intensity of 19 fatigue and illness-related symptoms during the month preceding the interview; these include all the CFS-defining symptoms (post-exertional fatigue, unrefreshing sleep, problems remembering and concentrating, muscle aches and pains, joint pain, sore throat, tender lymph nodes and swollen glands, and headaches).Perceived frequency of each symptom was rated on a five-point scale $(0-4)$ time), and severity or intensity of symptoms was measured on a four-point scale $(0-3)$. Individual symptom scores were calculated by multiplying the frequency score by the intensity score. For this purpose the intensity scores were transformed into equidistant scores $(0,1,2.5$ and 4$)$ before multiplication resulting in range $0-16$ for each symptom [46]. The CDC score contained the summed score of the 19 symptoms. Furthermore, the CDC score was divided into 2 subgroups: the CFS score and the CDC rest score. The $8 \mathrm{CFS}$ defining symptoms are post-exertional fatigue, unrefreshing sleep, problems remembering or concentrating, muscle aches and pains, joint pains, sore throat, tender lymph nodes and swollen glands, and headaches. In the CFS diagnostic criteria memory and concentration difficulties are taken as one combined symptom, whereas in the CDC inventory these 2 symptoms are scored separately. Therefore, for the CFS score the 9 above mentioned symptoms were summed. The 10 remaining CDC questions, not related to the CFS score, were also summed and labeled as CDC rest score.

\subsection{Statistical Analysis}

Scores were tested for normal distribution using the Shapiro-Wilk test in SPSS 
(IBM SPSS version 21). All data were normally distributed, except for the CDC rest scores pre and post curcumin use. Normally distributed data were presented as mean $\pm \mathrm{SD}$, the CDC rest scores as median $\pm \mathrm{IQR}$. Data were compared with Student' $t$ test for paired and unpaired data, where appropriate. A p value $<0.05$ was considered significantly different.

\section{Results}

Table 1 shows the demographic data. 35 females and 9 males were included. Mean disease duration was $17 \pm 10$ years. Except for length and weight, there were no differences between males and females (data not shown).

Table 2 shows the CDC inventory results. After 8 weeks of curcumin use, both the total CDC scores and the CFS scores were significantly lower ( $p<0.05$ and $\mathrm{p}<0.01$, respectively), compared to pre curcumin use. The reduction of the total CDC score was due to the significant reduction of the CFS score, the CDC rest score did not change significantly.

$\mathrm{ME}$ and atypical ME patients were analyzed separately in Table 3.

The pre curcumin CDC and CFS scores were significantly lower in the atypical ME group compared to the ME group. Similarly, the CDC and CFS scores post curcumin use were also significantly lower in the atypical ME group compared to the ME group. In both patients groups a significant reduction in the CFS score was observed, while the remaining symptoms did not change significantly.

Table 1. Baseline data.

\begin{tabular}{cc}
\hline No of patients & 44 \\
\hline CFS (\%) & $44(100 \%)$ \\
ME/atypical ME (\%) & $32 / 12(73 / 27 \%)$ \\
Gender F/M (\%) & $35 / 9(80 / 20 \%)$ \\
Age (years) & $47 \pm 11$ \\
Disease duration (years) & $17 \pm 10$ \\
Length (cm) & $173 \pm 8$ \\
Weight (kg) & $71 \pm 15$ \\
BMI & $23.6 \pm 3.8$ \\
SBP (mmHg) & $136 \pm 15$ \\
DBP (mmHg) & $82 \pm 8$ \\
HR (bpm) & $74 \pm 12$ \\
\hline
\end{tabular}

Table 2. CDC inventory for all patients $(\mathrm{n}=44)$.

\begin{tabular}{lccc}
\hline & Pre curcumin & 8 wks curcumin & p value \\
\hline CDC sympt. score (mean \pm SD) & $91 \pm 38$ & $79 \pm 40$ & $<0.05$ \\
CFS sympt. score (mean \pm SD) & $59 \pm 25$ & $51 \pm 25$ & $<0.01$ \\
CDC rest score (median \pm IQR) & $30 \pm 28$ & $26 \pm 22$ & ns \\
\hline
\end{tabular}

Sympt.: symptom; wks: weeks. 
Table 3. CDC inventory for CFS in ME $(n=32)$ and atypical ME $(n=12)$ patients.

\begin{tabular}{cccc}
\hline & Pre curcumin & 8 wks curcumin & p value \\
\hline ME pat: CDC sympt. score & $103 \pm 36^{* * * *}$ & $93 \pm 34^{* * * *}$ & $\mathrm{~ns}$ \\
ME pat: CFS sympt. score & $66 \pm 23^{\# \# \#}$ & $59 \pm 21^{\# \# *}$ & $<0.05$ \\
ME pat: CDC rest score & $37 \pm 21^{\text {0oo }}$ & $34 \pm 18^{\circ 000}$ & $\mathrm{~ns}$ \\
& & & \\
atyp ME :CDC sympt. score & $57 \pm 21$ & $43 \pm 30$ & $<0.05$ \\
atyp ME :CFS sympt.score & $39 \pm 18$ & $30 \pm 22$ & $<0.05$ \\
atyp ME: CDC rest score & $18 \pm 7$ & $13 \pm 10$ & $<0.05$ \\
\hline
\end{tabular}

Atyp: atypical; wks: weeks; sympt.: symptom; ME vs atyp ME CDC sympt. score ${ }^{* * * *}$ : $p<0.001 ;$ ME vs atyp ME CFS sympt. score \#\#: $\mathrm{p}<0.005$; \#\#\#: $\mathrm{p}<0.001$; ME vs atyp ME CDC rest score: ${ }^{\circ 000}$ : $\mathrm{p}<0.001$.

Figure 1 shows the difference in the total CDC, CFS score and CDC rest score between pre and 8 weeks of curcumin use in all patients, in ME and atypical ME patients.

\section{Discussion}

To the best of our knowledge, this is the first study that indicates that curcumin use has a positive effect on symptoms in ME/CFS patients as assessed by the CDC inventory for CFS. The CDC inventory consists of a combination of symptoms which are typical for ME/CFS patients and of other less specific symptoms. The data show that especially the typical CFS symptom scores are significantly reduced by the use of curcumin. The changes in the other symptoms are not significant. Symptoms may include a perpetualflu-likestate, sorethroats, tender/swollen lymph nodes, muscle pain, achy joints without swelling or redness, headaches, chills, "feverishness" and sensitivities to foods, odors, and medications [30], and are indicative for inflammation. As increased oxidative stress and altered cytokine patterns have been demonstrated in ME/CFS [33]-[42], it is likely that curcumin exerts its beneficial effects by the anti-oxidative [1], and anti-inflammatory [2] properties. However, the exact mechanism needs to be determined. Moreover, ME/CFS is considered to be in part a neuro-inflammatory disease [48] [49]. Curcumin passes the blood-brain barrier [50] and it is therefore tempting to assign the positive effects to an anti-oxidative and anti-inflammatory effect in the brains. This also needs to be determined.

The uptake of curcumin is low. In relation with the administration form, encapsulation in liposomes, polymeric nanoparticles, cyclodextrin encapsulation, lipid complexes or by synthesis of polymer-curcumin complex have been investigated [19]. All of them have helped increase the activity and bioavailability [51]. In this study curcumin complexed with phosphatidyl choline was used. Previous studies showed that curcumin bioavailability was increased over unprocessed curcumin [52] [53]. Our study indicates a modest effect of curcumin on symptom relief. Possibly a higher curcumin dose may result in a larger effect. 


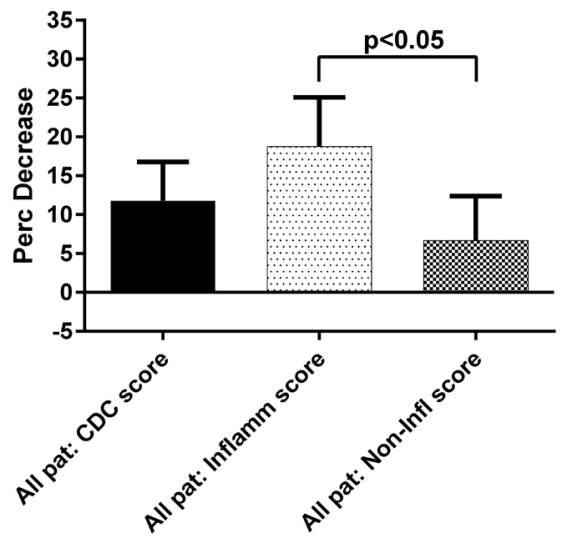

(a)

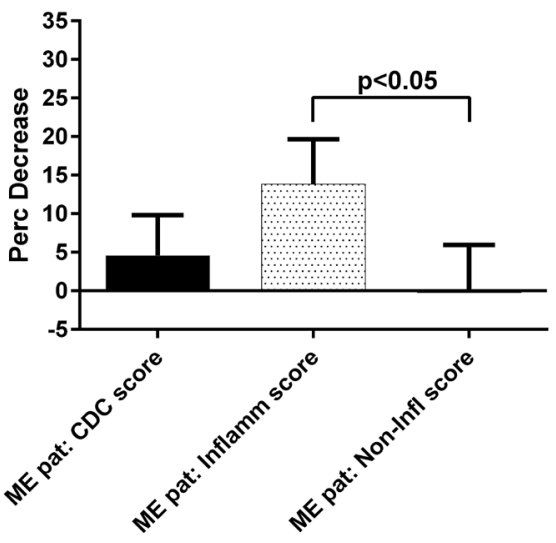

(b)

Figure 1. (a) Difference between the CDC, CFS score and CDC rest score pre and post 8 weeks of curcumin use for all patients. Data are presented as mean \pm SEM; (b) Difference between the CDC, CFS score and CDC rest score pre and post 8 weeks of curcumin use for patients meeting the ME criteria. Data are presented as mean \pm SEM.

Since the introduction of the ME criteria there has been a continuous debate whether CFS and ME are the same or different diseases [54] [55]. In this study all patients were diagnosed as having CFS and a subset of $72 \%$ of patients met the criteria for ME. Patients with ME had a significantly higher CDC, CFS and CDC rest symptom scores than the patients with CFS and atypical ME. This is in line with previous studies of Jason et al. [56] [57] suggesting that CFS and ME are not different but merely are a continuum in disease severity expression. However, more importantly, the favorable effects of curcumin are both present in CFS and in ME patients.

Unexpectedly, a relatively high number of ME/CFS patients ( $\mathrm{n}=6,10 \%)$ stopped the use of curcumin because of side effects. The explanation may be that multiple chemical sensitivities are prevalent in ME/CFS patients. In the study of Brown and Jason, the co-occurrence was almost 24\% [58]. It is unclear whether the drug itself or added excipients cause the intolerance.

\section{Limitations}

This study was an open-labeled study, without a placebo arm. A high number of patients $(\mathrm{n}=8,14 \%)$ did not return the first or second questionnaire, possibly leading to bias. A number of patients in the outpatient clinic admitted that they had difficulties with filling-in the questionnaire. This is most probably due to their memory and concentration problems, a disabling feature of the disease. A supervised fill-in approach may overcome this problem.

\section{Conclusion}

In this open-labeled study, 8-week curcumin use in a phosphatidyl choline complex reduced ME/CFS symptomatology. A randomized placebo controlled study is warranted to assess its efficacy in ME/CFS patients. 


\section{Conflicts of Interest}

FC Visser: none, CMC van Campen: none.

\section{Funding}

No financial support was obtained.

\section{Author Agreement/Declaration}

All authors have seen and approved the final version of the manuscript being submitted. They warrant that the article is the authors' original work, hasn't received prior publication and isn't under consideration for publication elsewhere.

\section{References}

[1] Joe, B. and Lokesh, B.R. (1994) Role of Capsaicin, Curcumin and Dietary n-3 Fatty Acids in Lowering the Generation of Reactive Oxygen Species in Rat Peritoneal Macrophages. Biochimica et Biophysica Acta, 1224, 255-263.

https://doi.org/10.1016/0167-4889(94)90198-8

[2] Joe, B., Vijaykumar, M. and Lokesh, B.R. (2004) Biological Properties of Curcumin-Cellular and Molecular Mechanisms of Action. Critical Reviews in Food Science and Nutrition, 44, 97-111. https://doi.org/10.1080/10408690490424702

[3] Mahady, G.B., Pendland, S.L., Yun, G. and Lu, Z.Z. (2002) Turmeric (Curcuma longa) and Curcumin Inhibit the Growth of Helicobacter Pylori, a Group 1 Carcinogen. Anticancer Research, 22, 4179-4181.

[4] Reddy, R.C., Vatsala, P.G., Keshamouni, V.G., Padmanaban, G. and Rangarajan, P.N. (2005) Curcumin for Malaria Therapy. Biochemical and Biophysical Research Communications, 326, 472-474. https://doi.org/10.1016/j.bbrc.2004.11.051

[5] Wright, L.E., Frye, J.B., Gorti, B., Timmermann, B.N. and Funk, J.L. (2013) Bioactivity of Turmeric-Derived Curcuminoids and Related Metabolites in Breast Cancer. Current Pharmaceutical Design, 19, 6218-6125. https://doi.org/10.2174/1381612811319340013

[6] Abdel-Daim, M.M. and Abdou, R.H. (2015) Protective Effects of Diallyl Sulfide and Curcumin Separately against Thallium-Induced Toxicity in Rats. Cell Journal, 17, 379-388.

[7] Kang, J., Chen, J., Shi, Y., Jia, J. and Zhang, Y. (2005) Curcumin-Induced Histone Hypoacetylation: The Role of Reactive Oxygen Species. Biochemical Pharmacology, 69, 1205-1213. https://doi.org/10.1016/j.bcp.2005.01.014

[8] Reddy, A.C. and Lokesh, B.R. (1994) Effect of Dietary Turmeric (Curcuma longa) on Iron-Induced Lipid Peroxidation in the Rat Liver. Food and Chemical Toxicology, 32, 279-283. https://doi.org/10.1016/0278-6915(94)90201-1

[9] Jeong, G.S., Oh, G.S., Pae, H.O., Jeong, S.O., Kim, Y.C., Shin, M.K., et al. (2006) Comparative Effects of Curcuminoids on Endothelial Heme Oxygenase-1 Expression: Ortho-Methoxy Groups Are Essential to Enhance Heme Oxygenase Activity and Protection. Experimental \& Molecular Medicine, 38, 393-400. https://doi.org/10.1038/emm.2006.46

[10] Reuter, S., Gupta, S.C., Chaturvedi, M.M. and Aggarwal, B.B. (2010) Oxidative Stress, Inflammation, and Cancer: How Are They Linked? Free Radical Biology \& Medicine, 49, 1603-1616. https://doi.org/10.1016/j.freeradbiomed.2010.09.006 
[11] Sethi, G., Sung, B. and Aggarwal, B.B. (2008) Nuclear Factor- $\kappa$ B Activation: From Bench to Bedside. Experimental Biology and Medicine (Maywood), 233, 21-31. https://doi.org/10.3181/0707-MR-196

[12] Anthwal, A., Thakur, B.K., Rawat, M.S., Rawat, D.S., Tyagi, A.K. and Aggarwal, B.B. (2014) Synthesis, Characterization and in Vitro Anticancer Activity of C-5 Curcumin Analogues with Potential to Inhibit TNF-Alpha-Induced NF-KappaB Activation. BioMed Research International, 2014, Article ID: 524161. https://doi.org/10.1155/2014/524161

[13] Cho, J.W., Lee, K.S. and Kim, C.W. (2007) Curcumin Attenuates the Expression of IL-1beta, IL-6, and TNF-Alpha as Well as Cyclin E in TNF-Alpha-Treated HaCaT Cells; NF- $\kappa \mathrm{B}$ and MAPKs as Potential Upstream Targets. International Journal of Molecular Medicine, 19, 469-474.

[14] Li, R., Wang, Y., Liu, Y., Chen, Q., Fu, W., Wang, H., et al. (2013) Curcumin Inhibits Transforming Growth Factor-betal-Induced EMT via PPAR $\gamma$ Pathway, Not Smad Pathway in Renal Tubular Epithelial Cells. PLOS ONE, 8, e58848. https://doi.org/10.1371/journal.pone.0058848

[15] Ruiz de Porras, V., Bystrup, S., Martinez-Cardus, A., Pluvinet, R., Sumoy, L., Howells, L., et al. (2016) Curcumin Mediates Oxaliplatin-Acquired Resistance Reversion in Colorectal Cancer Cell Lines through Modulation of CXC-Chemokine/NF- $\kappa$ B Signalling Pathway. Scientific Reports, 6, Article ID: 24675. https://doi.org/10.1038/srep24675

[16] Paulino, N., Paulino, A.S., Diniz, S.N., de Mendonca, S., Goncalves, I.D., Faiao Flores, F., et al. (2016) Evaluation of the Anti-Inflammatory Action of Curcumin Analog (DM1): Effect on iNOS and COX-2 Gene Expression and Autophagy Pathways. Bioorganic \& Medicinal Chemistry, 24, 1927-1935. https://doi.org/10.1016/j.bmc.2016.03.024

[17] Nieto, C.I., Cabildo, M.P., Cornago, M.P., Sanz, D., Claramunt, R.M., Torralba, M.C., et al. (2015) Fluorination Effects on NOS Inhibitory Activity of Pyrazoles Related to Curcumin. Molecules, 20, 15643-15665. https://doi.org/10.3390/molecules200915643

[18] Huang, C.Z., Huang, W.Z., Zhang, G. and Tang, D.L. (2013) In Vivo Study on the Effects of Curcumin on the Expression Profiles of Anti-Tumour Genes (VEGF, CyclinD1 and CDK4) in Liver of Rats Injected with DEN. Molecular Biology Reports, 40, 5825-5831. https://doi.org/10.1007/s11033-013-2688-y

[19] Pulido-Moran, M., Moreno-Fernandez, J., Ramirez-Tortosa, C. and Ramirez-Tortosa, M. (2016) Curcumin and Health. Molecules, 21, 264.

https://doi.org/10.3390/molecules21030264

[20] Pari, L., Tewas, D. and Eckel, J. (2008) Role of Curcumin in Health and Disease. Archives of Physiology and Biochemistry, 114, 127-149.

https://doi.org/10.1080/13813450802033958

[21] Tenero, L., Piazza, M., Zanoni, L., Bodini, A., Peroni, D. and Piacentini, G.L. (2016) Antioxidant Supplementation and Exhaled Nitric Oxide in Children with Asthma. Allergy \& Asthma Proceedings, 37, 8-13. https://doi.org/10.2500/aap.2016.37.3920

[22] Ahn, J.K., Kim, S., Hwang, J., Kim, J., Lee, Y.S., Koh, E.M., et al. (2015) Metabolomic Elucidation of the Effects of Curcumin on Fibroblast-Like Synoviocytes in Rheumatoid Arthritis. PLoS ONE, 10, e0145539.

https://doi.org/10.1371/journal.pone.0145539

[23] Lang, A., Salomon, N., Wu, J.C., Kopylov, U., Lahat, A., Har-Noy, O., et al. (2015) Curcumin in Combination with Mesalamine Induces Remission in Patients with Mild-to-Moderate Ulcerative Colitis in a Randomized Controlled Trial. Clinical 
Gastroenterology and Hepatology, 13, 1444-1449e1.

[24] Rainey-Smith, S.R., Brown, B.M., Sohrabi, H.R., Shah, T., Goozee, K.G., Gupta, V.B., et al. (2016) Curcumin and Cognition: A Randomised, Placebo-Controlled, Double-Blind Study of Community-Dwelling Older Adults. British Journal of $\mathrm{Nu}$ trition, 115, 2106-2113. https://doi.org/10.1017/S0007114516001203

[25] Yu, J.J., Pei, L.B., Zhang, Y., Wen, Z.Y. and Yang, J.L. (2015) Chronic Supplementation of Curcumin Enhances the Efficacy of Antidepressants in Major Depressive Disorder: A Randomized, Double-Blind, Placebo-Controlled Pilot Study. Journal of Clinical Psychopharmacology, 35, 406-410. https://doi.org/10.1097/JCP.0000000000000352

[26] Mahammedi, H., Planchat, E., Pouget, M., Durando, X., Cure, H., Guy, L., et al. (2016) The New Combination Docetaxel, Prednisone and Curcumin in Patients with Castration-Resistant Prostate Cancer: A Pilot Phase II Study. Oncology, 90, 69-78. https://doi.org/10.1159/000441148

[27] Yang, H., Xu, W., Zhou, Z., Liu, J., Li, X., Chen, L., et al. (2015) Curcumin Attenuates Urinary Excretion of Albumin in Type II Diabetic Patients with Enhancing Nuclear Factor Erythroid-Derived 2-Like 2 (Nrf2) System and Repressing Inflammatory Signaling Efficacies. Experimental and Clinical Endocrinology \& Diabetes, 123, 360-367. https://doi.org/10.1055/s-0035-1545345

[28] Panahi, Y., Rahimnia, A.R., Sharafi, M., Alishiri, G., Saburi, A. and Sahebkar, A. (2014) Curcuminoid Treatment for Knee Osteoarthritis: A Randomized Double-Blind Placebo-Controlled Trial. Phytotherapy Research, 28, 1625-1631. https://doi.org/10.1002/ptr.5174

[29] Akazawa, N., Choi, Y., Miyaki, A., Tanabe, Y., Sugawara, J., Ajisaka, R., et al. (2012) Curcumin Ingestion and Exercise Training Improve Vascular Endothelial Function in Postmenopausal Women. Nutrition Research, 32, 795-799.

https://doi.org/10.1016/j.nutres.2012.09.002

[30] IOM (2015) Beyond Mayalgic Encephalomyelitis/Chronic Fatigue Syndrome: Redefining an Illness. The National Academies Press, Washington DC.

[31] Twisk, F.N. (2014) The Status of and Future Research into Myalgic Encephalomyelitis and Chronic Fatigue Syndrome: The Need of Accurate Diagnosis, Objective Assessment, and Acknowledging Biological and Clinical Subgroups. Frontiers in Physiology, 5, 109. https://doi.org/10.3389/fphys.2014.00109

[32] Jason, L.A. and Richman, J.A. (2008) How Science Can Stigmatize: The Case of Chronic Fatigue Syndrome. Journal of Chronic Fatigue Syndrome, 14, 85-103. https://doi.org/10.1080/10573320802092146

[33] Morris, G., Berk, M., Walder, K. and Maes, M. (2015) Central Pathways Causing Fatigue in Neuro-Inflammatory and Autoimmune Illnesses. BMC Medicine, 13, 28. https://doi.org/10.1186/s12916-014-0259-2

[34] Nijs, J., Nees, A., Paul, L., De Kooning, M., Ickmans, K., Meeus, M., et al. (2014) Altered Immune Response to Exercise in Patients with Chronic Fatigue Syndrome/Myalgic Encephalomyelitis: A Systematic Literature Review. Exercise Immunology Review, 20, 94-116.

[35] Maes, M., Bosmans, E. and Kubera, M. (2015) Increased Expression of Activation Antigens on CD8+ T Lymphocytes in Myalgic Encephalomyelitis/Chronic Fatigue Syndrome: Inverse Associations with Lowered CD19+ Expression and CD4+/CD8+ Ratio, But No Associations with (auto)immune, Leaky Gut, Oxidative and Nitrosative Stress Biomarkers. Neuro Enocrinology Letters, 36, 439-446.

[36] Jason, L., Sorenson, M., Sebally, K., Alkazemi, D., Lerch, A., Porter, N., et al. (2011) 
Increased HDAC in Association with Decreased Plasma Cortisol in Older Adults with Chronic Fatigue Syndrome. Brain, Behavior, and Immunity, 25, 1544-1547. https://doi.org/10.1016/j.bbi.2011.04.007

[37] Morris, G., Anderson, G., Dean, O., Berk, M., Galecki, P., Martin-Subero, M., et al. (2014) The Glutathione System: A New Drug Target in Neuroimmune Disorders. Molecular Neurobiology, 50, 1059-1084. https://doi.org/10.1007/s12035-014-8705-x

[38] Blundell, S., Ray, K.K., Buckland, M. and White, P.D. (2015) Chronic Fatigue Syndrome and Circulating Cytokines: A Systematic Review. Brain, Behavior, and Immunity, 50, 186-195. https://doi.org/10.1016/j.bbi.2015.07.004

[39] Russell, L., Broderick, G., Taylor, R., Fernandes, H., Harvey, J., Barnes, Z., et al. (2016) Illness Progression in Chronic Fatigue Syndrome: A Shifting Immune Baseline. BMC Immunology, 17, 3. https://doi.org/10.1186/s12865-016-0142-3

[40] Landi, A., Broadhurst, D., Vernon, S.D., Tyrrell, D.L. and Houghton, M. (2016) Reductions in Circulating Levels of IL-16, IL-7 and VEGF-A in Myalgic Encephalomyelitis/Chronic Fatigue Syndrome. Cytokine, 78, 27-36.

https://doi.org/10.1016/j.cyto.2015.11.018

[41] Hornig, M., Montoya, J.G., Klimas, N.G., Levine, S., Felsenstein, D., Bateman, L., et al. (2015) Distinct Plasma Immune Signatures in ME/CFS Are Present Early in the Course of Illness. Science Advances, 1, e1400121. https://doi.org/10.1126/sciadv.1400121

[42] Hornig, M., Montoya, J.G., Klimas, N.G., Levine, S., Felsenstein, D., Bateman, L., et al. (2016) Distinct Plasma Ebrospinal Fluid in Myalgic Encephalomyelitis/Chronic Fatigue Syndrome. Molecular Psychiatry, 21, 261-269.

https://doi.org/10.1038/mp.2015.29

[43] Gupta, A., Vij, G., Sharma, S., Tirkey, N., Rishi, P. and Chopra, K. (2009) Curcumin, a Polyphenolic Antioxidant, Attenuates Chronic Fatigue Syndrome in Murine Water Immersion Stress Model. Immunobiology, 214, 33-39. https://doi.org/10.1016/j.imbio.2008.04.003

[44] Fukuda, K., Straus, S.E., Hickie, I., Sharpe, M.C., Dobbins, J.G. and Komaroff, A. (1994) The Chronic Fatigue Syndrome: A Comprehensive Approach to Its Definition and Study. International Chronic Fatigue Syndrome Study Group. Annals of Internal Medicine, 121, 953-959. https://doi.org/10.7326/0003-4819-121-12-199412150-00009

[45] Carruthers, B.M., van de Sande, M.I., DE Meirleir, K.L., Klimas, N.G., Broderick, G., Mitchell, T., et al. (2011) Myalgic Encephalomyelitis: International Consensus Criteria. Journal of Internal Medicine, 270, 327-338. https://doi.org/10.1111/j.1365-2796.2011.02428.x

[46] Wagner, D., Nisenbaum, R., Heim, C., Jones, J.F., Unger, E.R. and Reeves, W.C. (2005) Psychometric Properties of the CDC Symptom Inventory for Assessment of Chronic Fatigue Syndrome. Population Health Metrics, 3, 8. https://doi.org/10.1186/1478-7954-3-8

[47] Vermeulen, R.C. (2006) Translation and Validation of the Dutch Language Version of the CDC Symptom Inventory for Assessment of Chronic Fatigue Syndrome (CFS). Population Health Metrics, 4, 12. https://doi.org/10.1186/1478-7954-4-12

[48] Morris, G., Berk, M., Galecki, P., Walder, K. and Maes, M. (2016) The Neuro-Immune Pathophysiology of Central and Peripheral Fatigue in Systemic Immune-Inflammatory and Neuro-Immune Diseases. Molecular Neurobiology, 53, 1195-219. https://doi.org/10.1007/s12035-015-9090-9

[49] Nakatomi, Y., Mizuno, K., Ishii, A., Wada, Y., Tanaka, M., Tazawa, S., et al. (2014) 
Neuroinflammation in Patients with Chronic Fatigue Syndrome/Myalgic Encephalomyelitis: An 11C-(R)-PK11195 PET Study. Journal of Nuclear Medicine, 55, 945-950. https://doi.org/10.2967/jnumed.113.131045

[50] Ryu, E.K., Choe, Y.S., Lee, K.H., Choi, Y. and Kim, B.T. (2006) Curcumin and Dehydrozingerone Derivatives: Synthesis, Radiolabeling, and Evaluation for Beta-Amyloid Plaque Imaging. Journal of Medicinal Chemistry, 49, 6111-6119. https://doi.org/10.1021/jm0607193

[51] Prasad, S., Tyagi, A.K. and Aggarwal, B.B. (2014) Recent Developments in Delivery, Bioavailability, Absorption and Metabolism of Curcumin: The Golden Pigment from Golden Spice. Cancer Research and Treatment, 46, 2-18. https://doi.org/10.4143/crt.2014.46.1.2

[52] Marczylo, T.H., Verschoyle, R.D., Cooke, D.N., Morazzoni, P., Steward, W.P. and Gescher, A.J. (2007) Comparison of Systemic Availability of Curcumin with That of Curcumin Formulated with Phosphatidylcholine. Cancer Chemotherapy and Pharmacology, 60, 171-177. https://doi.org/10.1007/s00280-006-0355-X

[53] Gupta, N.K. and Dixit, V.K. (2011) Bioavailability Enhancement of Curcumin by Complexation with Phosphatidyl Choline. Journal of Pharmaceutical Sciences, 100, 1987-1995. https://doi.org/10.1002/jps.22393

[54] Maes, M., Twisk, F.N. and Johnson, C. (2012) Myalgic Encephalomyelitis (ME), Chronic Fatigue Syndrome (CFS), and Chronic Fatigue (CF) Are Distinguished Accurately: Results of Supervised Learning Techniques Applied on Clinical and Inflammatory Data. Psychiatry Research, 200, 754-760. https://doi.org/10.1016/j.psychres.2012.03.031

[55] Jason, L.A., Brown, A., Evans, M., Sunnquist, M. and Newton, J.L. (2013) Contrasting Chronic Fatigue Syndrome versus Myalgic Encephalomyelitis/Chronic Fatigue Syndrome. Fatigue, 1, 168-183. https://doi.org/10.1080/21641846.2013.774556

[56] Jason, L.A., McManimen, S., Sunnquist, M., Brown, A., Furst, J., Newton, J.L., et al. (2016) Case Definitions Integrating Empiric and Consensus Perspectives. Fatigue, 4, 1-23. https://doi.org/10.1080/21641846.2015.1124520

[57] Jason, L.A., Evans, M., Brown, A., Sunnquist, M. and Newton, J.L. (2015) Chronic Fatigue Syndrome versus Sudden Onset Myalgic Encephalomyelitis. Journal of Prevention \& Intervention in the Community, 43, 62-77. https://doi.org/10.1080/10852352.2014.973233

[58] Brown, M.M. and Jason, L.A. (2007) Functioning in Individuals with Chronic Fatigue Syndrome: Increased Impairment with Co-Occurring Multiple Chemical Sensitivity and Fibromyalgia. Dynamic Medicine, 6, 9.

https://doi.org/10.1186/1476-5918-6-9 